\title{
RELEVANSI KEMAMPUAN ALUMNI PROGRAM STUDI TEKNIK SIPIL TERHADAP DUNIA KERJA
}

\author{
Mahdi $^{1)}$ \\ ${ }^{1)}$ Dosen Jurusan Teknik Sipil Fakultas Teknik Universitas Almuslim(Umuslim) Bireuen Aceh \\ mahugha3utg@gmail.com
}

\begin{abstract}
ABTRACT
Competitive world of construction to create quality jobs in accordance with the wishes of the people are increasingly high, not only large contractors are trying as much as possible, medium and even small contractors will strive to improve the quality of work in accordance with the wishes of the people. This study aims to determine how relevant competence factors include knowledge, skills, and attitudes gained from the lectures of Civil Engineering University Almuslim with the needs in the world of work as well as knowing the difference of perception based on the role of the respondents (contractors and consultants) and work experience of respondents (under 4 year, 4 to 8 years, over 8 years). This research was conducted by distributing a questionnaire addressed to alumni of the University of Civil Engineering Program Almuslim that work to contractors and consultants who are directly involved in a construction project. Furthermore, all kuesoiner which were collected and analyzed statistically using the analysis Independent Sample T-test, and one way Analysis of Variance (ANOVA) using SPSS. From the analysis we found that the factor most relevant competences between the educational curriculum of Civil Engineering University Almuslim with the needs of the workforce total is "Reinforcement and Expenses Detail Bending, Axial, Slide, and Torque" on knowledge. For the skill aspect, the greatest subvariable is "Being able to become independent learners follow the development of science in civil engineering". For the aspects of attitude, the highest subvariable is "Experience". In addition, from the results of the analysis showed that there was no difference of perception based on the role and experience of the respondents.
\end{abstract}

Keywords: Relevance, Capabilities, Competencies.

\section{PENDAHULUAN}

Persaingan dunia kontruksi untuk menciptakan mutu pekerjaan yang sesuai dengan keinginan masyarakat yang semakin tinggi, tidak hanya kontraktor besar saja yang berusaha semaksimal mungkin , kontraktor menengah dan kecilpun akan berusaha meningkatkan mutu pekerjaan sesuai dengan keinginan masyarakat. Untuk itu setiap perusahaan kontruksi terus melakukan inovasi untuk menjaga kualitas produk dan kepuasan konsumen, karena kunci perusahan tetap eksis selalu memperhatikan kualitas proyek yang dikerjakan. Hal ini perlu diperhatikan karena adanya kenyataan bahwa penyedia proyek yang tidak puas akan mencari kontraktor lain yang mampu memuaskan pemberi proyek.

Melihat hal tersebut diatas perlu dilakukan evaluasi terhadap ketrampilan dan kemampuan pada lulusan perguruan tinggi, terutama alumni Program Studi Teknik Sipil, agar lulusannya siap dan fleksibel terhadap tantangan dunia kerja, serta mampu memenuhi dan menyenangkan para pengguna lulusan ini. Bila kemampuan yang mareka miliki sesuai harapan maka penyedia proyek akan mengunakan jasa mareka, bila tidak sesuai harapan maka lulusan tersebut tidak digunakan lagi sehingga mareka akan sangat sulit mendapatkan pekerjaaan.

Undang-Undang (UU) No. 13 Tahun 2003 tentang Ketenagakerjaan pasal 1 ayat 10 menyebutkan bahwa kompetensi adalah kemampuan kerja setiap individu yang mencakup aspek pengetahuan, keterampilan, dan sikap kerja yang sesuai dengan standar yang ditetapkan. Penelitian ini ingin 
mengetahui seberapa besar relevansi antara kompetensi alumni Program Studi Teknik Sipil Universitas Umuslim yang akan ditinjau dari 3 aspek yaitu pengetahuan (knowledge), keterampilan (skill), dan sikap (attitude) dengan kebutuhan dunia kerja. Penelitian ini juga membahas analisis perbedaan persepsi berdasarkan peran dan pengalaman responden.

\section{KAJIAN LITERATUR}

\subsection{Pengetahuan (Knowledge)}

Menurut (Nadler, 1986) Kompetensi adalah kemampuan yang dibutuhkan untuk melakukan pekerjaan yang dilandasi oleh pengetahuan, keterampilan, dan sikap. Pengetahuan merupakan proses belajar manusia mengenai kebenaran atau jalan yang benar atau secara mudah yaitu mengetahui apa yang harus diketahui dan untuk dilakukan. Aspek pengetahuan dibagi meliputi 4 penjurusan Teknik Sipil yang meliputi desain struktur, manajemen, hidro, dan transportasi

1. Manajemen

a. Manajemen Keselamatan Kesehatan Kerja terdiri dari, Melakukan Perencanaan K3, Melaksanakan dan Mengendalikan K3 ,Melakukan Pencapaian Hasil Pelaksanaan K3.

b. Manajemen Lingkungan terdiri dari, Mengidentifikasi Dampak Pelaksanaan Proyek Terhadap Lingkungan, Upaya Pengelolaan dan Pemantauan Lingkungan Proyek, Melakukan Audit Lingkungan Proyek.

c. Manajemen Keuangan terdiri dari, Melakukan Perencanaan Keuangan Proyek, Melakukan Proses Pengendalian Keuangan Proyek Melakukan Pencatatan dan Administrasi Keuangan Proyek.

d. Manajemen Waktu terdiri dari, Melakukan Penetapan Jadwal Waktu Pelaksanaan Proyek, Menerapkan dan Mengendalikan Jadwal Waktu Pelaksanaan Proyek, Menilai Hasil/Progress Jadwal Waktu Pelaksanaan Proyek.

e. Manajemen Mutu terdiri dari, Melakukan Perencanaan Mutu, Melakukan Pelaksanaan Jaminan Mutu Proyek ,Melakukan Proses Peningkatan Mutu Secara Terus Menerus.

f. Manajemen Resiko terdiri dari, Menganalisis Resiko, Merencanakan Resiko, Mengontrol Resiko.

2. Struktur

a. Struktur Baja terdiri dari, Metode Dalam Analisis Struktur Baja, Pemahaman Komponen Lentur, Tekan, dan Tarik ,Pemahaman Struktur Komposit, Pemahaman Sambungan Baja.

b. Struktur Beton terdiri dari, Detail Tulangan, Analisis dan Desain Pertimbangan Umum (Metode Desain, Pembebanan, dan Kemampuan Layan), Persyaratan Kekuatan dan Kemampuan Layan Beban Lentur, Axial, Geser, dan Torsi Sistem Slab dua arah Komponen Struktur Cangkang dan Pelat Lipat dan Evaluasi Kekuatan Struktur

c. Perencanaan Ketahanan Gempa terdiri dari, Perencanaan Umum Struktur Bangunan Gedung, Kriteria Desain Untuk Dinding Penumpu atau Rangka Bangunan Sederhana, Perencanaan Desain Seismik pada Elemen Non Struktural Prosedur Respons, Riwayat Waktu Gempa Struktur dengan Isolasi Dasar.

d. Mekanika Tanah terdiri dari, Deskripsi dan Klasifikasi Tanah, Metode Penyelidikan Tanah, Metode Pemadatan Tanah ,Prinsip Tekanan Efektif dan Rembesan Air, Interaksi Tanah-Struktur untuk Desain Bangunan Konsolidasi, Penurunan, dan Kekuatan Geser Daya Dukung Tanah Perencanaan Pondasi.

3. Hidro

a. Bangunan Air terdiri dari, embung, bendung, bendungan, elivasi dan debit air.

b. Sistem Irigasi terdiri dari, Pompanisasi, bendung, jaringan irigasi dan saluran.

4. Trasportasi

a. Sistem Transportasi terdiri dari, Sarana trasportasi, jenis-jenis trasportasi.

b. Prasarana Transportasi terdiri dari, Jembatan, pelabuhan, terminal, jalan raya, laut, sungai. 


\subsection{Keterampilan}

Keterampilan adalah kemampuan yang harus dimiliki untuk melaksanakan beberapa tugas yang merupakan pengembangan dari hasil training dan pengalaman yang didapat.

1. Individual Skill adalah Kontak Formal atau Perencanaan Menerapkan aturan dengan kemampuan yang flexibel dan mudah beradaptasi, Memahami tugas lainnya Keahlian dalam bidang masingmasing.

2. Special Skill adalah Mampu menjadi pembelajar mandiri dalam mengikuti perkembangan ilmu teknik sipil, Mampu mengimplementasikan ilmu teknik sipil sesuai dengan kebutuhan masyarakat.

\subsection{Sikap}

Menurut Robbins, sikap merupakan pernyataan evaluatif, baik yang menyenangkan maupun tidak menyenangkan terhadap objek, individu, atau peristiwa .

1. Contextual Performance Behaviours

a. Job Dedication (Komitmen dalam mencapai tujuan proyek berdasarkan dengan bertakwa kepada Tuhan Yang Maha Esa dan menunjukkan sikap religius).

b. Interpersonal facilitation (Penyelesaian konflik dengan menjunjung tinggi nilai kemanusiaan berdasarkan agama, moral, dan etika).

2. Task Performance Behaviours

a. Cognitive ability (Penyegaran progress dengan menjaga emosional berdasarkan nilai, norma, dan etika akademik).

b. Task Proficiency (Spesifikasi kualitas teknik dalam pekerjaan teknik sipil dengan sikap bertanggung jawab secara mandiri, dan jiwa kewirausahawan).

c. Experience (Pengalaman dalam mencapai keberhasilan proyek dengan penuh ketaatan hukum, disiplin dalam bermasyarakat dan bernegara)

\subsection{Metode dan Instrumen Pengumpulan Data}

Metode pengumpulan data adalah cara yang dapat digunakan oleh peneliti untuk mengumpulkan data. Yang terdaftar dalam metode pengumpulan data adalah : angket (questionnaire), wawancara, pengamatan, test, dokumentasi, dll.

Instrumen pengumpulan data adalah alat bantu yang dipilih dan digunakan oleh peneliti dalam kegiatan mengumpulkan data agar kegiatan tersebut menjadi sistematis dan mudah.

\subsection{Reliabilitas Alat ukur}

Reliabilitas Alat ukur berkenaan denganderajat konsistensi dan stabilitas datayang dihasilkan dari proses pengumpulan data dengan menggunakan instrumen tersebut. Ada dua aukuran yang sering digunakan untuk mengetahui derajat reliabiitas instumen pengumpulan data yaitu stabilitas intrumen dan konsistensi internal instrumen.

\subsection{Validitas alat ukur}

Validitas data adalah suatu ukuran yang mengacu kepada derajat kesesuaian antara data yang dikumpulkan dan data yang sebenarnya dalam sumber data. Data yang valid akan diperoleh apabila instrumen pengumpulan data juga valid.

\subsection{Skala Penilaian}

Skala Penilaian adalah untuk mengetahui karakteristik sesuatu hal berdasrkan ukuran tertentu, sehingga dapat membedakan, memgolongkan, bahkan mengurutkan karakteristik tersebut. Skala penilaian dapat di klasifiksikan dalam empat karakteristik sistem bilangan yaituaa: skala nominal, skala ordinal, skala interval dan skala rasio. 


\section{METODOLOGI}

Jenis penelitian yang digunakan dalam penelitian ini adalah penelitian deskriptif kuantitatif. Penelitian deskriptif kuantitatif merupakan penelitian yang bertujuan untuk mengetahui status dan mendeskripsikan suatu fenomena berdasarkan data yang terkumpul (Silalahi, 2006). Populasi dalam penelitian ini adalah alumni Program Studi Teknik Sipil Universitas Alamuslim yang bekerja sebagai kontraktor dan konsultan. Sedangkan sampel adalah sub kelompok dari elemen-elemen populasi yang dipilih untuk berpartisipasi dalam penelitian ini. Pengukuran indikator variabel dalam penelitian ini menggunakan skala Likert, yaitu dengan menyusun pernyataan yang masing-masing item diberi range skor dalam skala Likert yang dapat dilihat pada Tabel 1. Pada kuesioner ini, para responden diminta untuk mengisi seberapa besar relevan variabel pengetahuan, keterampilan, dan sikap yang didapat dari perkuliahan Teknik Sipil Universitas Almuslim dengan kebutuhan responden di dunia kerja.

Tabel 1. Skala Likert

\begin{tabular}{|l|l|}
\hline Keterangan & Skor \\
\hline Sangat Relevan & 5 \\
\hline Relevan & 4 \\
\hline Netral & 3 \\
\hline Tidak Relevan & 2 \\
\hline Sangat Tidak Relevan & 1 \\
\hline
\end{tabular}

\section{HASIL DAN ANALISIS}

\subsection{Gambaran Umum Objek Penelitian}

Berdasarkan data, diketahui bahwa responden yang mengisi kuesioner pada survei ini berjumlah 120 responden. Kemudian dibuat kategori responden berdasarkan peran, pendidikan terakhir, tahun lulus, dan pengalaman kerja responden di bidang jasa konstruksi. Untuk tahun kelulusan responden tersebar dari tahun 2005 sampai 2016, dengan jumlah responden terbanyak tahun 2015 sebanyak 15 orang. Untuk data responden mencakup data peran, pendidikan terakhir, dan pengalaman kerja responden dapat dilihat pada Tabel 2.

Tabel 2. Data Responden

\begin{tabular}{|c|c|c|c|}
\hline No & Data Responden & Keterangan & $\begin{array}{l}\text { Jumlah Responden } \\
\text { (orang) }\end{array}$ \\
\hline \multirow[t]{2}{*}{1} & \multirow[t]{2}{*}{ Peran Responden } & Kontraktor & 79 \\
\hline & & Konsultan & 41 \\
\hline \multirow{3}{*}{2} & \multirow{3}{*}{ Pendidikan Terakhir } & $\mathrm{S} 1$ & 85 \\
\hline & & S2 & 34 \\
\hline & & S3 & 1 \\
\hline \multirow{3}{*}{3} & \multirow{3}{*}{ Pengalaman Kerja } & $<4$ tahun & 68 \\
\hline & & 4-8 tahun & 39 \\
\hline & & $>8$ tahun & 13 \\
\hline
\end{tabular}

\subsection{Hasil Uji Validitas dan Reliabilitas Kuesioner}

Uji validitas digunakan untuk mengukur sah atau valid tidaknya suatu kuesioner. Langkah dalam menguji validitas butir pertanyaan pada kuesioner yaitu mencari nilai corrected Item-Total correlation. Setiap pernyataan dinyatakan valid apabila corrected item total correlation yang dihasilkan di atas $\mathrm{r}$ tabel, yaitu sebesar 0,1874. Besar corrected item total correlation tiap variabel hasil output SPSS menunjukkan bahwa semua variabel memiliki nilai corrected item-total correlation $>0,1874$. Maka dapat disimpulkan 
bahwa kuesioner yang digunakan telah valid dan mampu mengukur tiap variabel yang digunakan dalam penelitian ini.

\subsection{Hasil Uji Validitas dan Reliabilitas Kuesioner}

Pengujian realibilitas untuk data persepsi resonden dilakukan untuk mengetahui apakah kuisioner yang telah dibuat realibel atau tidak. Reliabilitas menunjukkan konsistensi dan stabilitas dari suatu skor atau skala pengukuran (Simamora, 2002). Uji reliabilitas adalah hasil cronbach alpha $>0,6$. Jika alpha yang dinilai lebih besar dari 0,6, maka item-item yang digunakan dalam kuesioner dapat disebut reliabel (Ghozali, 2005). Dari hasil output SPSS menunjukkan bahwa semua variabel yang digunakan dalam penelitian ini memiliki nilai Cronbach's Alpha > 0,600. Dengan demikian, dapat disimpulkan bahwa semua variabel dianggap reliabel, karena jawaban yang diberikan responden terhadap kuesioner relatif konsisten dan bisa digunakan untuk analisis selanjutnya.

\subsection{Analisis Tingkat Relevansi}

Hasil analisis tingkat relevansi berguna untuk mengetahui seberapa besar tingkat relevansi faktorfaktor kompetensi meliputi pengetahuan, keterampilan, dan sikap didapatkan di perkuliahan Teknik Sipil Universitas Almuslim dengan kebutuhan di dunia kerja. Berikut ini dapat dilihat pada Tabel 3. hasil analisis tingkat relevansi dengan nilai mean terbesar untuk kontraktor, konsultan, dan nilai mean secara total. Tingginya nilai mean menandakan bahwa variabel tersebut yang pernah didapatkan di perkuliahan banyak dipakai dan menjawab kebutuhan kontraktor dan konsultan di dunia kerja.

Tabel 3. Hasil Analisis Tingkat Relevansi

\begin{tabular}{|c|c|c|c|c|c|}
\hline \multirow{2}{*}{$\begin{array}{l}\mathrm{N} \\
\mathrm{o}\end{array}$} & \multirow[t]{2}{*}{ Aspek } & \multirow[t]{2}{*}{ Sub Variabel } & \multicolumn{3}{|c|}{ Mean } \\
\hline & & & Kontraktor & Konsultan & Total \\
\hline & \multirow{3}{*}{ Pengetahuan } & $\begin{array}{l}\text { Detail Tulangan danBeban Lentur, Axial, } \\
\text { Geser, dan Torsi }\end{array}$ & 4,574 & \multirow{3}{*}{4,447} & 4,511 \\
\hline \multirow[t]{2}{*}{1} & & Pemahaman Sambungan Baja & & & \\
\hline & & Sistem Slab Dua Arah & & & \\
\hline \multirow[t]{2}{*}{2} & \multirow[t]{2}{*}{ Keterampilan } & $\begin{array}{l}\text { Mampu berinovasi dengan belajar mandiri } \\
\text { dalam mengikuti perkembangan teknik } \\
\text { sipil }\end{array}$ & 4,128 & & 4,136 \\
\hline & & $\begin{array}{l}\text { Mampu mengikuti perkembangan ilmu } \\
\text { dan teknologi dalam bidang teknik sipil }\end{array}$ & & 4,249 & \\
\hline \multirow{3}{*}{3} & \multirow{3}{*}{ Sikap } & Job Dedication & 4,090 & & \\
\hline & & Task Proficiency & & 4,203 & \\
\hline & & Experience & & & 4,109 \\
\hline
\end{tabular}

\subsection{Analisis Perbedaan Persepsi Berdasarkan Peran Responden}

Analisis perbedaan persepsi antara peran responden yang terbagi menjadi kontraktor dan konsultan dalam menjawab kuesioner dilakukan untuk mengetahui perbedaan jawaban antara kontraktor dan konsultan mengenai seberapa besar tingkat relevansi faktor-faktor kompetensi meliputi pengetahuan, keterampilan, dan sikap yang didapat di perkuliahan Program Studi Teknik Sipil Universitas Almuslim dengan kebutuhan di dunia kerja. Uji analisis perbedaan persepsi berdasarkan peran responden ini dilakukan dengan Independent Sample T-Test dapat dilihat pada Tabel 4. Hipotesis penelitian ini dinyatakan sebagai berikut:

H0 = Tidak ada perbedaan persepsi yang signifikan antara jawaban kontraktor dan konsultan.

H1 = Ada perbedaan persepsi yang signifikan antara jawaban kontraktor dan konsultan 
Tabel 4. Hasil Analisis Perbedaan Persepsi Berdasarkan Peran Responden

\begin{tabular}{|c|l|l|c|}
\hline Aspek & \multicolumn{1}{|c|}{ Variabel } & \multicolumn{1}{|c|}{ Sub Variabel } & Keterangan Ho \\
\hline Pengetahuan & Manajemen Resiko & \multicolumn{1}{|c|}{} & \\
\cline { 2 - 4 } & Manajemen Keuangan & $\begin{array}{l}\text { Melakukan Pencatatan dan Administrasi } \\
\text { Keuangan Proyek }\end{array}$ & Ditolak \\
\cline { 2 - 4 } & Manajemen Mutu & $\begin{array}{l}\text { Melakukan Proses Peningkatan Mutu } \\
\text { Secara Terus Menerus }\end{array}$ & Ditolak \\
\cline { 2 - 4 } & Manajemen Waktu & $\begin{array}{l}\text { Melakukan Penetapan Jadwal Waktu } \\
\text { Pelaksanaan Proyek }\end{array}$ & Ditolak \\
\cline { 2 - 4 } & & $\begin{array}{l}\text { Menerapkan dan Mengendalikan Jadwal } \\
\text { Waktu Pelaksanaan Proyek }\end{array}$ & Ditolak \\
\cline { 2 - 4 } & Manajemen K3 & $\begin{array}{l}\text { Melakukan Pencapaian } \\
\text { Pelaksanaan K3 Han }\end{array}$ & Ditolak \\
\cline { 2 - 4 } & & Melakukan Perencanaan K3 & Ditolak \\
\hline
\end{tabular}

Pengetahuan terdiri dari 51 variabel, variabel yang menyatakan bahwa Ho ditolak karena ada perbedaan persepsi yang signifikan antara jawaban kontraktor dan konsultan terdapat 8 sub variabel.. Perbedaan persepsi antara kontraktor dan konsultan disebabkan oleh perbedaan ruang lingkup pekerjaan, dimana kontraktor lebih sering berada di lapangan untuk melakukan kegiatan pelaksanaan dan pengawasan proyek sedangkan konsultan lebih banyak berada di kantor untuk melakukan perencanaan struktur bangunan. Sedangkan Untuk variabel keterampilan dan sikap, Ho diterima semua sehingga dapat diambil kesimpulan bahwa tidak ada perbedaan persepsi yang signifikan antara jawaban kontraktor dan konsultan.

\subsection{Analisis Perbedaan Persepsi Berdasarkan Pengalaman Kerja Responden}

Perbedaan persepsi dapat dianalisis berdasarkan pengalaman kerja dilakukan dengan analisa One Way Analysis of Variance (ANOVA). Analisis perbedaan persepsi berdasarkan pengalaman kerja ini dilakukan dengan membagi responden berdasarkan lama tahun pengalaman kerja menjadi 3 kelompok besar yaitu kelompok dengan pengalaman kerja dibawah 4 tahun, pengalaman kerja 4 sampai 8 tahun, dan pengalaman kerja diatas 8 tahun dapat dilihat pada Tabel 5. Hipotesis penelitian ini dinyatakan sebagai berikut : $\mathrm{H} 0$ = Tidak ada perbedaan persepsi tentang pengetahuan, keterampilan, dan sikap yang signifikan berdasarkan tahun pengalaman. H1 = Ada perbedaan persepsi tentang pengetahuan, keterampilan, dan sikap yang signifikan berdasarkan tahun pengalaman.

Tabel 5. Hasil ANOVA Perbedaan Persepsi Berdasarkan Pengalaman Kerja Responden

\begin{tabular}{|l|l|l|l|l|l|l|}
\hline \multicolumn{2}{|l|}{} & $\begin{array}{l}\text { Sum of } \\
\text { Squares }\end{array}$ & df & $\begin{array}{l}\text { Mean } \\
\text { Square }\end{array}$ & F & Sig. \\
\hline & Between Groups & 0,368 & 2 & 0,181 & 0,695 & 0,511 \\
\hline Pengetahuan & Within Groups & 27,564 & 107 & 0,259 & & \\
\hline & Total & 27,932 & 109 & & & \\
\hline & Between Groups & 1,089 & 2 & 0,543 & 1,704 & 0,193 \\
\hline Keterampilan & Within Groups & 33,888 & 107 & 0,317 & & \\
\hline & Total & 34,977 & 109 & & & \\
\hline & Between Groups & 0,014 & 2 & 0,005 & 0,013 & 0,989 \\
\hline Sikap & Within Groups & 44,757 & 107 & 0,423 & & \\
\hline & Total & 44,771 & 109 & & & \\
\hline
\end{tabular}

Pada Tabel 5. dapat dilihat bahwa pada kolom Sig. diketahui nilai P-value adalah pengetahuan 0,511, keterampilan 0,193, dan sikap 0,989. Dengan demikian nilai signifikan pada ketiga aspek lebih besar dari 0,05, sehingga dapat disimpulkan bahwa H0 diterima. Hal ini berarti tidak ada perbedaan 
persepsi antar 3 kelompok pengalaman kerja yaitu kelompok dengan pengalaman kerja dibawah 4 tahun, pengalaman kerja 4 sampai 8 tahun, dan pengalaman kerja diatas 8 tahun. Tidak adanya perbedaan persepsi antara para responden yang dibagi berdasarkan 3 kelompok pengalaman kerja ini disebabkan oleh materi yang diberikan di perkuliahan sudah mengikuti perkembangan yang selalu update di dunia kerja sehingga tingkat relevansi antara dunia pendidikan dengan dunia kerja tetap tinggi menurut semua responden.

\section{KESIMPULAN}

1. Untuk konsultan, sub variabel yang paling tinggi relevansinya adalah Pemahaman Sambungan Baja pada variabel Struktur Baja, Detail Tulangan, dan Sistem Slab Dua Arah pada variabel Struktur Beton. untuk kontraktor Aspek pengetahuan, sub variabel yang paling tinggi relevansinya adalah Detail Tulangan dan Beban Lentur, Axial, Geser, dan Torsi pada variabel Struktur Beton.

2. Untuk aspek keterampilan, sub variabel yang paling tinggi relevansinya untuk kontraktor adalah mampu menjadi pembelajar mandiri dalam mengikuti perkembangan ilmu teknik sipil pada variabel Special Skill. Untuk konsultan, sub variabel yang paling tinggi relevansinya adalah mampu mengikuti perkembangan ilmu dan teknologi dalam bidang teknik sipil pada variabel Special Skill.

3. Pada aspek sikap, sub variabel yang paling tinggi relevansinya untuk kontraktor adalah Job Dedication pada variabel Contextual Performance Behaviours. sedangkan konsultan, sub variabel yang paling tinggi relevansinya adalah Task Proficiency dan Experience pada variabel Task Performance Behaviours.

4. Secara keseluruhan tidak ada perbedaan persepsi berdasarkan peran responden yaitu kontraktor dan konsultan serta berdasarkan tahun pengalaman bekerja responden, yang terbagi menjadi 3 kelompok yaitu pengalaman bekerja dibawah4 tahun, pengalaman kerja 4 sampai 8 tahun, dan pengalaman kerja diatas 8 tahun mengenai tingkat relevansi faktor-faktor kompetensi meliputi pengetahuan, keterampilan, dan sikap yang didapatkan di perkuliahan Program Studi Teknik Sipil Universitas Almuslim dengan kebutuhan dunia kerja.

\section{DAFTAR PUSTAKA}

Djarwanto PS, 1998 “ Statistik sosial Ekonomi “. Edisi 2. Yogyakarta:BPPE

Ghozali, I. 2005. Aplikasi Analisis Multivariate dengan Program SPSS, Badan Penerbit Universitas Diponegoro, Semarang

Nadler, G. 1986. Terobosan Cara Berpikir, Southern University, California.

Republik Indonesia. 2003. Undang-Undang No. 13 tahun 2003 tentang Ketenagakerjaan, Sekretariat Negara, Jakarta. Robbins, S.P. \& Judge. (2007). Perilaku Organisasi, Salemba Empat, Jakarta.

Simamora, B. 2002. Panduan Riset Perilaku Konsumen, Gramedia Pustaka Utama, Jakarta.

Supranto J. 2001. ”Pengukuran Tingkat Kepuasan Pelanggan”. Jakarta: Rineka Cipta. 